THURSDAY. OCTOBER $24,1907$.

\section{WAY-SIDE FRUITS.}

Wild Fruits of the Country-side. By F. Edward Hulme. Pp. $x+22 x ;$ illustrated. (London: Hutchinsoh and $\mathrm{Co}_{\text {: }}$, 190\%) Pripd: 5 s. net.

THE subject of this bookj forie that may be most 1 convenienty the autumn season, when so many ktees fa e fidruiting condition. Mr. Hulme has witttur 24/pages; which are illustrated with thirty-ixi full-page coloured drawings, prepared by the author, and twenty-five half-tone pictures, which are reproductions from photographs. There are three chapters, and the species of plants are grouped into these chapters as follows :-Chapter $i$., plants of the hedgerows; chapter ii., trees of the forest; and chapter iii., plants of the moorland, the meadow and the stream.

The notes vary in length according to the estimated importance and interest of the species, and the text is largely composed of quotations from the old writers on the folk-lore of the species, and medicinal uses to which parts of the plants have been applied. The author attempts to trace in most cases the derivation of the names, and, in addition, supplies brief descriptions of the structure of the flowers and fruits. We have nothing but praise for the coloured plates, which in all instances appear sufficiently faithful to nature to enable the novice to identify the fruits, notwithstandirig the drawings lack such botanical details as can only be shown after dissection of the fruits, and illustration of the sections. Those representing the common spindle tree (Euonymus europaeus), hawthorn (Crataegus oxyacantha), sweet briar (Rosa rubiginosa), and oak (Quercus Robur) are especially commendable.

Having said so much as to the merits of the book, we cannot be silent in respect to its defects. The text has evidently been written hurriedly, and the composition needed more careful revision than has been exercised. The following sentence, for instance, is not more ambiguous than many others that might be selected from each chapter. On p. ${ }_{13}$, in respect to the privet (Ligustrum vulgare) the author writes :-

"After. these somewhat offensive or altogether delightful flowers succeed the berries, and these, if unmolested by the blackbirds, thrushes, bullfinches, and other birds to whom they are acceptable, remain on the plant throughout the winter."

The punctuation is reproduced faithfully. Or, as on p. 203 :-

"Large tracts have, however, of late years been ploughed up, a proceeding little to the benefit of anyone, and, so far as it goes destructive of a wild beauty that might well, hava been suffered to remain, and which we, Staffordshire-born, can only regret the loss"!

On p. ${ }^{4}$, in a sentence which fefers to the privet, the word generic has been made to read genuine. On p. $5^{2}$ the yew (Taxus baccata) is referred to as NO. 1982 . VOL. 76$]$ a genuine ancient Briton," but on p. 57 it is alse described as "a welcome and sturdy guest," which is surely, suggestive of an exotic -species rather than " an ancient Briton."

The use that is made of capital letters is altogether, incorisistent. In the headings all the specific names commence with capitals, a practice which is indefensible when applied to botanical nomenclature, yet on p. i8I Viscum cruciatum, when printed in the text, has no capitals, not even one for the generic name.

We can see no reason for the author adopting the out-of-date name Sarothamnus for the common broom, the correct name for which is Cytisus. The plant should be invariably described as Cytisus scoparius. The list of illustrations at the commencement of the book has probably escaped the author's revision after the type was set. This would explain the generic word Rubus being misspelt Robus in three instanees, and scoparius misspelt scaparius.

The subject of this work is an extremely interesting one, and notwithstanding the imperfections we have mentioned, the book may be' recommended to those who are about to spend a holiday in a country district, or to students in schoods but especially to those who desire to acquire sorne knowledge of the folk-lore connected with some of the commonest fruiting plants in our native flora.

\section{COSMOLOGICAI. SPECULATION.}

Two New Worlds. (1) The Infra-World; (2) The Supra-World. By E. E. Ous ler d'Albe. Pp. ix + I57. (London: Kongn and Co., 1907.) Price 3s. 6 d. net.

THE hrstpart of this book is an elaboration of an 1 atalop already familiar to the scientific public, The If fra-world is a universe in which an earthly atom is a solar system: the positive atom is its sun, the electrons are its planets. The author points out that the scale of distances in our own and the infraworld is approximately in the ratio $1 \mathrm{O}^{22}: \mathrm{I}$, this being the ratio of the average diameters of our solar system and an atom. Further, the infra-year, measured by the period of revolution of an electron about its positive atom, is, for a particular case, reduced by the same factor. In this coincidence Mr. Fournier finds justification for regarding the world of atoms as a veritable universe on a smaller scale.

The detailed account of the Inframworld which is presented in the first six chapters, though interesting in itself, is perhaps to be regarded mainly as prepar: ing the way for the conception of a Supra-world, in which our solar system functions as an, atam. It is not possible here to discuss the reasoning by which the author secks to ettablish the existence of ultragalactic universes; the warguments he employs are simple and reasonable and will appeal strongly to the reader who is willing to be guided by: probability in a region where logical certainty is at present unattainable. It is suffieient here to remark that the author's prosentation of the 'Supra-world is based on the assimptitions:- 